\title{
Therapeutic Doses of Oral Methylphenidate Significantly Increase Extracellular Dopamine in the Human Brain
}

\author{
Nora D. Volkow, ${ }^{1,3}$ Gene-Jack Wang, ${ }^{1}$ Joanna S. Fowler, ${ }^{2}$ Jean Logan, ${ }^{2}$ Madina Gerasimov, ${ }^{2}$ \\ Laurence Maynard,, ${ }^{1}$ Yu-Shin Ding, ${ }^{2}$ Samuel J. Gatley, ${ }^{1}$ Andrew Gifford, ${ }^{1}$ and Dinko Franceschi ${ }^{1}$ \\ Departments of ${ }^{1}$ Medical and ${ }^{2}$ Chemistry, Brookhaven National Laboratory, Upton, New York 11973, and ${ }^{3}$ Department of \\ Psychiatry, State University of New York at Stony Brook, Stony Brook, New York 11794
}

\begin{abstract}
Methylphenidate (Ritalin) is the most commonly prescribed psychoactive drug in children for the treatment of attention deficit hyperactivity disorder (ADHD), yet the mechanisms responsible for its therapeutic effects are poorly understood. Whereas methylphenidate blocks the dopamine transporter (main mechanism for removal of extracellular dopamine), it is unclear whether at doses used therapeutically it significantly changes extracellular dopamine (DA) concentration. Here we used positron emission tomography and $\left[{ }^{11} \mathrm{C}\right]$ raclopride (D2 receptor radioligand that competes with endogenous DA for binding to the receptor) to evaluate whether oral methylphenidate changes extracellular DA in the human brain in 11 healthy controls. We showed that oral methylphenidate (average dose $0.8 \pm 0.11 \mathrm{mg} / \mathrm{kg}$ ) significantly increased extracellular DA in brain, as evidenced by a significant reduction in $B_{\max } / K_{\mathrm{d}}$ (measure of D2 receptor availability) in striatum $(20 \pm 12 \% ; p<$ $0.0005)$. These results provide direct evidence that oral methylphenidate at doses within the therapeutic range significantly increases extracellular DA in human brain. This result coupled
\end{abstract}

with recent findings of increased dopamine transporters in ADHD patients (which is expected to result in reductions in extracellular DA) provides a mechanistic framework for the therapeutic efficacy of methylphenidate. The increase in DA caused by the blockade of dopamine transporters by methylphenidate predominantly reflects an amplification of spontaneously released DA, which in turn is responsive to environmental stimulation. Because DA decreases background firing rates and increases signal-to-noise in target neurons, we postulate that the amplification of weak DA signals in subjects with ADHD by methylphenidate would enhance task-specific signaling, improving attention and decreasing distractibility. Alternatively methylphenidate-induced increases in DA, a neurotransmitter involved with motivation and reward, could enhance the salience of the task facilitating the "interest that it elicits" and thus improving performance.

Key words: attention deficit hyperactivity disorder; raclopride; Ritalin; D2 receptors; striatum; positron emission tomography; imaging; dopamine transporters
Attention deficit hyperactivity disorder (ADHD) is the most common behavioral disorder of childhood; its prevalence is estimated to be $5-10 \%$ of the general population (Swanson et al., 1998). An increase in recognition of ADHD over the past decade has led to a dramatic increase in the prescription of methylphenidate (MP) (Ritalin), the drug of choice in the treatment of ADHD (Swanson et al., 1995). Although MP has been used therapeutically for the past 50 years, its mechanism or mechanisms of action are poorly understood. MP is a stimulant drug that blocks the dopamine (DA) and the norepinephrine transporter, and it is hypothesized that these pharmacological actions are relevant to its therapeutic effects (Solanto, 1998). Particularly relevant are its effects on DA transporters (DAT) in view of the recent findings documenting significant increases in DAT in subjects with ADHD (Dougherty et al., 1999; Krause et al. 2000) and the reported association between expression of the DAT1 allele and scores of hyperactivity-impulsivity in subjects with ADHD

\footnotetext{
Received Sept. 20, 2000; revised Oct. 17, 2000; accepted Oct. 18, 2000.
}

This research was performed at Brookhaven National Laboratory under support of the United States Department of Energy OBER under Contract DE- $\mathrm{ACO}_{2}$ $76 \mathrm{CH} 00016$ and by the National Institute on Drug Abuse Grants DA09490-01 and DA06891-06. We thank D. Schlyer for Cyclotron operations, D. Warner for PET operations, C. Wong for data management, R. Ferrieri, K. Shea, R. MacGregor, and P. King for radiotracer preparation and analysis, N. Pappas, N. Netusil, and Pauline Carter for patient care, and T. Cooper for plasma methylphenidate analyses.

Correspondence should be addressed to Nora D. Volkow, Medical Department, Brookhaven National Laboratory, Upton, NY 11973. E-mail: volkow@bnl.gov. Copyright (C) 2001 Society for Neuroscience 0270-6474/01/210001-05\$15.00/0
(Waldman et al., 1998). We have shown that therapeutic doses of oral MP (0.25-1 mg/ kg) induced significant DAT blockade (50$75 \%$ ) in the human brain (Volkow et al., 1998). Because DAT is the main mechanism for removal of extracellular DA in brain (Giros et al., 1996), one could predict that oral MP should increase extracellular DA. In fact, it has been hypothesized that MP acts by increasing resting levels of extracellular DA, which stimulate DA autoreceptors attenuating DA release in response to activation (Seeman and Madras, 1998). However, no study has been done to assess whether oral MP at the doses used therapeutically increases extracellular DA in the human brain. Although MP, when given intravenously, increases extracellular DA in the human brain (Volkow et al., 1994, 1999a; Booij et al., 1997), one cannot predict similar findings with oral MP, which is the route of

This article is published in The Journal of Neuroscience, Rapid Communications Section, which publishes brief, peerreviewed papers online, not in print. Rapid Communications are posted online approximately one month earlier than they would appear if printed. They are listed in the Table of Contents of the next open issue of JNeurosci. Cite this article as: JNeurosci, 2001, 21:RC121 (1-5). The publication date is the date of posting online at www.jneurosci.org.

http://www.jneurosci.org/cgi/content/full/4896 
administration used therapeutically, because in addition to differences in bioavailability, the route of administration significantly affects the effects of stimulant drugs presumably via its effects on pharmacokinetics (Verebey and Gold, 1988). This is particularly relevant for MP because it is abused when taken intravenously but rarely so when taken orally (Parran and Jasinski, 1991). Because the ability of stimulants such as cocaine and MP to increase extracellular DA is linked to their reinforcing effects (Ritz et al., 1987), it was also of relevance to determine whether the reason why oral MP is rarely abused is because it does not sufficiently increase extracellular DA.

The purpose of this study was to assess if oral MP at doses used therapeutically increases extracellular DA in the human brain. This was done using positron emission tomography (PET) and $\left[{ }^{11} \mathrm{C}\right]$ raclopride, a DA D2 receptor radioligand sensitive to competition with DA, a property that can be used to measure druginduced changes in extracellular DA (Volkow et al., 1994). Because $\left[{ }^{11} \mathrm{C}\right]$ raclopride binding is highly reproducible (Volkow et al., 1993), differences in binding between placebo and drug predominantly reflect drug-induced changes in extracellular DA (Dewey et al., 1993).

\section{MATERIALS AND METHODS}

Subjects. The participants were 11 male healthy subjects (age $30 \pm 7$ years, SD; weight, $172 \pm 23 \mathrm{lb}$ ) who did not have a present or past history of drug or alcohol abuse or dependence as per the Diagnostic and Statistical Manual of Mental Disorders IV (excluding nicotine or caffeine). Subjects were excluded if they had a current or past psychiatric, neurological, cardiovascular, or endocrinological disease. None of the subjects was taking medications at the time of the study. Toxicological drug screens were performed before each PET scan. The protocol was approved by the Institutional Review Board at Brookhaven National Laboratory, and subjects gave written informed consent to participate.

Scans. Subjects had two scans done with $\left[{ }^{11} \mathrm{C}\right]$ raclopride, the first scan done $60 \mathrm{~min}$ after placebo (saline tablet), and the second done $60 \mathrm{~min}$ after $60 \mathrm{mg}$ of oral MP. The scans were performed $2 \mathrm{hr}$ apart from each other, and the subjects were blind to whether placebo or oral MP was administered. Scans were done using a CTI 931 tomograph $(6 \times 6 \times 6.5$ $\mathrm{mm}$ full width half maximum) after intravenous injection of $4-10 \mathrm{mCi}$ of $\left[{ }^{11} \mathrm{C}\right.$ ]raclopride (specific activity $0.5-1.5 \mathrm{Ci} / \mu \mathrm{M}$ at end of bombardment; $2-24 \mu \mathrm{g}$ of injected dose) for a series of 20 emission scans obtained through $60 \mathrm{~min}$; the procedure used has been described elsewhere (Volkow et al., 1993). Arterial plasma samples were obtained throughout the procedures to quantify plasma concentration of ${ }^{11} \mathrm{C}$ and of "nonmetabolized" $\left[{ }^{11} \mathrm{C}\right]$ raclopride and the plasma concentration of MP, which was quantified using capillary GC-mass spectrometry (Srinivas et al., 1991). Because of technical problems with some of the samples, measures of MP in plasma were only available for six subjects.

Drug effect ratings. Behavioral effects were evaluated using analog scales that assessed self reports of high alertness, anxiety, restlessness, and drug effects from 1 (felt nothing) to 10 (felt intensely) (Wang et al., 1997) recorded $5 \mathrm{~min}$ before placebo or MP and then every $5 \mathrm{~min}$ for a total of $120 \mathrm{~min}$. Recordings for heart rate and blood pressure were obtained continuously throughout the placebo and MP scans.

Image analysis and modeling. Regions of interest were outlined for striatum and cerebellum; the procedure used has been described elsewhere (Volkow et al., 1993). The time activity curves for the concentration of radiotracer in striatum (putamen) and in cerebellum obtained from the dynamic PET scans and the time activity curves for the concentration of radiotracer in arterial blood corrected for metabolites were used to obtain $\mathrm{K}_{1}$ (plasma to tissue transport constant) and the distribution volume (DV) using a graphical analysis technique for reversible systems (Logan et al., 1990). The ratio of DV in striatum to that in cerebellum, which corresponds to $\left(B_{\max } / K_{\mathrm{d}}\right)+1$ and is insensitive to changes in cerebral blood flow was used as model parameter to quantify D2 receptor availability (Logan et al., 1994). The response to MP was quantified as the difference in $B_{\max } / K_{\mathrm{d}}$ between placebo and MP and expressed as percent change from placebo.

Data analysis. Differences in $\mathrm{K}_{1}, \mathrm{DV}, B_{\max } / K_{\mathrm{d}}$ and in the behavioral and cardiovascular measures after placebo and after oral MP were tested
Table 1. Estimates for $K_{1}$ and distribution volumes (DV) for $\left[{ }^{11} \mathrm{C}\right]$ raclopride after placebo and after oral methylphenidate

\begin{tabular}{lll} 
& Placebo & Methylphenidate \\
\hline $\mathrm{K}_{1}$ & & \\
$\quad$ Cerebellum & $0.06 \pm 0.01$ & $0.06 \pm 0.01$ \\
$\quad$ Striatum & $0.09 \pm 0.01$ & $0.08 \pm 0.01$ \\
$\mathrm{DV}$ & $0.38 \pm 0.05$ & $0.36 \pm 0.05$ \\
$\quad$ Cerebellum & $1.80 \pm 0.27$ & $1.45 \pm 0.20^{*}$ \\
$\quad$ Striatum &
\end{tabular}

Values correspond to means and SDs.

${ }^{*} p<0.002$.

with repeated ANOVA. For the comparisons of the behavioral ratings we selected the peak effects, and for the comparisons of the cardiovascular measures we averaged the scores between 60 and $90 \mathrm{~min}$, which were the time periods when peak effects for MP occurred. Pearson product moment correlation analyses were calculated between the changes in $B_{\max } / K_{\mathrm{d}}$, age of the subjects, plasma MP concentration, and the behavioral changes (MP-placebo). Values of $p<0.01$ were considered significant, and $p$ values $>0.01<0.05$ are reported as trends.

\section{RESULTS}

\section{MP significantly increased DA}

MP did not affect the transport of $\left[{ }^{11} \mathrm{C}\right]$ raclopride from blood to brain $\left(\mathrm{K}_{1}\right)$ in striatum or in cerebellum nor did it affect the distribution volume (DV) in cerebellum (Table 1). In contrast, MP significantly reduced the DV in striatum $(F=18$; $\mathrm{df}=1,10$; $p<0.002$ ) (Table 1). This can be seen in Figure 1, which shows representative DV images for $\left[{ }^{11} \mathrm{C}\right]$ raclopride images at the level of striatum and at the level of the cerebellum obtained after placebo and after MP. MP significantly reduced the estimates for DA D2 receptor availability $\left(B_{\max } / K_{\mathrm{d}}\right)$ in striatum $(20 \pm 12 \%$; $F=26$; df $=1,10 ; p<0.0004$ ) (Fig. $2 A$ ). MP-induced changes in $B_{\text {max }} / K_{\mathrm{d}}$ showed a large intersubject variability (range, 3-48\%). The magnitude of the changes in $B_{\max } / K_{\mathrm{d}}$ were found to be inversely correlated with age $(r=0.73$; df $=10 ; p<0.01)$; the larger changes were observed in the youngest subjects (Fig. 2B).

\section{Behavioral effects of MP varied significantly across subjects}

None of the effects of MP on the behavioral measures reached statistical significance. However, there were trends for an increase in self reports of "high", "feel drug", and "restlessness" $(p<$ $0.05)$. The behavioral responses to MP were quite variable across subjects, and whereas six of the subjects reported minimal or no effects (peak ratings of $\leq 2$ ), three reported significant effects (peak ratings of $\geq 6$ ). The correlations between $B_{\max } / K_{\mathrm{d}}$ and the behavioral measures were not significant (Table 2).

Cardiovascular effects from MP were only significant for an increase in heart rate $(p<0.001)$ (Table 2$)$.

\section{No relationship between DA changes and plasma MP concentration}

Plasma concentrations of D-threo-methylphenidate (active enantiomer of methylphenidate), corresponded at 60 and at $120 \mathrm{~min}$ to $30 \pm 18 \mathrm{ng} / \mathrm{ml}$ and $34 \pm 12 \mathrm{ng} / \mathrm{ml}$, respectively. The levels of L-threo-methylphenidate (inactive enantiomer of methylphenidate) were undetectable. The changes in $B_{\max } / K_{\mathrm{d}}$ were not correlated with concentration of D-threo-methylphenidate in plasma. 


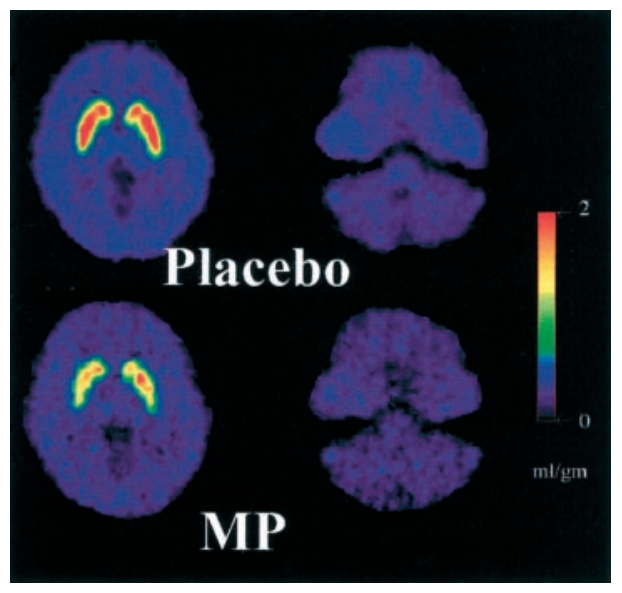

Figure 1. Distribution volume images of $\left[{ }^{11} \mathrm{C}\right]$ raclopride at the level of the striatum and at the level of the cerebellum for one of the subjects at baseline and after administration of $60 \mathrm{mg}$ of oral methylphenidate $(M P)$. MP reduced binding of $\left.{ }^{11} \mathrm{C}\right]$ raclopride in the striatum where it competes with dopamine (DA) for binding to DA D2 receptors, but not in cerebellum where binding is predominantly nonspecific.

\section{DISCUSSION}

\section{Significance of methylphenidate-induced increases in extracellular dopamine with regard to its therapeutic effects}

These results provide direct evidence that oral MP significantly increases extracellular DA concentration in human brain. The average weight-adjusted dose in this study corresponded to $0.8 \pm$ $0.11 \mathrm{mg} / \mathrm{kg}$, which is within the range used therapeutically for children with ADHD (0.25-1 mg/kg) (Greenhill et al., 1996). However, although some adults treated with oral MP receive 60 mg per administration, most receive $10-20 \mathrm{mg}$ per administration given two to four times a day. Thus, although the dose used in this study is higher than frequently used doses in adults, it is representative of what is used clinically. Moreover, because oral MP is given every $3-4 \mathrm{hr}$, and its half life in plasma is $\sim 4.5 \mathrm{hr}$ (Shader et al., 1999), with repeated administration, as done clinically, it is likely to result in higher tissue levels than those seen after a single dose.

These findings are in agreement with our results obtained in parallel microdialysis studies performed in rodents. In these studies we showed significant increases in extracellular DA after intragastric administration of $\mathrm{MP}$, at doses that maintained plasma concentrations equivalent to those seen therapeutically (Gerasimov et al., 2000). That MP increases extracellular DA in striatum is relevant in light of the recent reports showing that
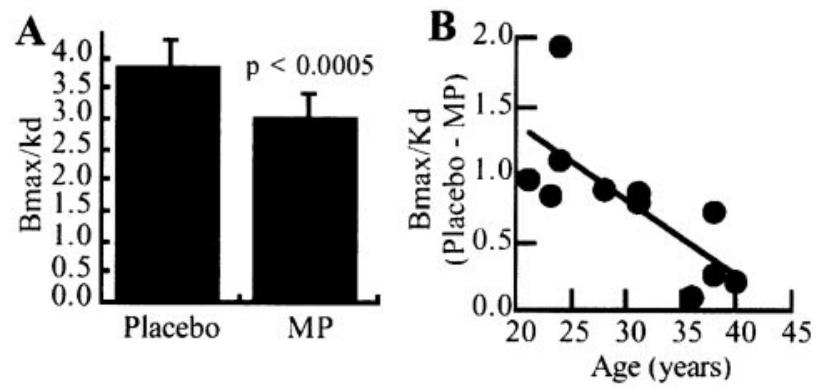

Figure 2. $A, B_{\max } / K_{\mathrm{d}}$ estimates in striatum after placebo and after methylphenidate $(M P)$. Comparison corresponds to repeated ANOVA. $B$, Regression between the changes in $B_{\max } / K_{\mathrm{d}}$ induced by MP (Placebo MP) and the age of the subjects; correlation value corresponds to $r=0.73$ $(p<0.01)$; MP effects were larger in the younger subjects.
Table 2. Behavioral and cardiovascular effects of placebo and of oral methylphenidate (MP)

\begin{tabular}{lclcc} 
& Placebo & Methylphenidate & $p$ & $r$ \\
\hline Behavioral measures & & & & \\
$\quad$ High & $1.5 \pm 1.5$ & $4.0 \pm 4$ & 0.03 & 0.19 \\
Anxiety & $2.5 \pm 2.7$ & $2.5 \pm 2.8$ & & 0.32 \\
Restlessness & $1.2 \pm 0.6$ & $2.8 \pm 2.9$ & 0.05 & 0.36 \\
Drug effect & $1.5 \pm 1.5$ & $4.3 \pm 3.6$ & 0.02 & 0.11 \\
$\quad$ Alert & $8.5 \pm 2.3$ & $8.9 \pm 1.7$ & & 0.30 \\
Cardiovascular measures & & & & \\
$\quad$ Heart rate & $63 \pm 8$ & $71 \pm 9$ & 0.001 & 0.12 \\
$\quad$ Systolic pressure & $122 \pm 14$ & $132 \pm 13$ & & 0.30 \\
$\quad$ Diastolic pressure & $62 \pm 9$ & $70 \pm 10$ & & 0.48 \\
\hline
\end{tabular}

Values for $p$ reflect comparisons from the repeated ANOVA, and the $r$ values correspond to the correlation coefficients between MP-induced changes in the behavioral and cardiovascular measures and the changes in DA; none were significant $(r>0.58 ; p<0.05)$.

subjects with ADHD have increases in striatal DAT (Dougherty et al., 1999; Krause et al. 2000), which is predicted to result in reductions in extracellular DA. Thus, the DA deficit in ADHD would be temporarily relieved by MP, which through DAT blockade significantly increases extracellular DA. MP is a DAT blocker (Kuczenski and Segal, 1997), and hence it amplifies DA release resultant from DA cell firing, which in turn is responsive to environmental stimulation (Overton and Clark, 1997). Because DA in striatum has been shown to decrease background firing rates and increase signal-to-noise ratio of striatal cells (Kiyatkin and Rebec, 1996), MP-induced increases in striatal DA are expected to enhance task-related neuronal cell firing. One could therefore speculate that the amplification of the weak DA signals in subjects with ADHD by MP would enhance task-specific signaling, improving attention and decreasing distractability. Alternatively, methylphenidate-induced increases in DA, a neurotransmitter involved with motivation and reward (Koob, 1996), could enhance the salience of the task facilitating the "interest that it elicits" and thus improving performance.

\section{Role of MP-induced increases in extracellular dopamine and its reinforcing effects}

The magnitude of DA increases after oral MP are comparable with those that we reported for intravenous MP (Volkow et al., $1999 \mathrm{a})$, at a dose $(0.5 \mathrm{mg} / \mathrm{kg})$ that occupied $\sim 78 \pm 11 \%$ of the DAT (Volkow et al., 1999b). This level of DAT occupancy is similar to the one we had previously shown after administration of $60 \mathrm{mg}$ of oral MP $(74 \pm 2 \%)$ (Volkow et al., 1998). However, after intravenous MP we observed a significant association between MP-induced DA increases and the reinforcing effects of MP, as assessed by self reports of "high" (Volkow et al., 1999a), which we did not see after oral MP. Also, despite similar levels of DAT blockade and of DA changes the self-reports of "high", after subtracting for placebo, were lower after oral $(2.5 \pm 3)$ than after intravenous MP (6.4 \pm 4$)$ (Volkow et al., 1999a). In explaining this apparent discrepancy, it is relevant to address the difference in the brain pharmacokinetics between intravenous and oral MP because faster delivery of drugs of abuse into the brain is associated with greater reinforcing effects (Balster and Schuster, 1973; Oldendorf, 1992). After oral administration, MP does not reach peak concentrations in brain until after $60 \mathrm{~min}$, whereas after intravenous administration, MP reaches peak concentrations in brain within 8-10 min (Volkow et al., 1995). Although we had 
initially hypothesized that oral MP had low reinforcing effects because its slow brain uptake resulted in adaptation responses that interfered with the increases in extracellular DA (Volkow et al., 1998), the results from this study do not support this hypothesis. Nor do they support the hypothesis that oral MP has low reinforcing effects because of its rapid metabolism into ritalinic acid, a compound with low psychostimulant actions (Faraj et al., 1974).

\section{MP-induced increases in extracellular dopamine varied significantly across subjects}

MP-induced changes in extracellular DA varied significantly across subjects (range, 3-48\%). This variability was not accounted by differences in metabolism of MP because the correlation between plasma MP concentration and MP-induced changes in DA was not significant. This contrasts with the studies in which levels of DAT occupancy by oral MP were significantly correlated with the plasma concentration of MP (Volkow et al., 1998). This is similar to our results with intravenous MP, which showed a much stronger correlation between plasma MP concentration and DAT blockade than with MP-induced changes in DA (Volkow et al., 1999a). We attributed this to the fact that the differences in the magnitude of MP-induced increases in DA are a function not only of the levels of DAT blockade but also of the levels at which DA is being released. One could therefore postulate that for an equivalent level of DAT blockade, MP would be more potent in a subject whose baseline release of DA is high than in a subject whose baseline release of DA is low. This is in line with findings that homovanillic acid levels in CSF, which serve as a marker of DA turnover in CNS, predicted response to MP in children with ADHD; the higher the levels, the better the responses (Castellanos et al., 1996). Although one could question whether increased DA release could also affect MP binding to DAT, this is unlikely because binding of MP to DAT is not affected by the levels of extracellular DA (Gatley et al., 1995).

\section{MP induced increase in extracellular dopamine decrease with age}

Methylphenidate-induced increases in DA declined as a function of age. An age-related blunting in stimulant-induced DA increases had also been observed after intravenous MP (Volkow et al., 1994) and after intravenous amphetamine (Laruelle et al., 1995). This could reflect the decrease in DAT that occurs with age because these are the molecular targets for both MP and amphetamine. In fact one could speculate that the age-associated decline in DAT could contribute to the decrease in symptomatology in most of the ADHD subjects as they grow older (Biederman, 1998). Alternatively the fact that the elevations of DAT in ADHD subjects were reported in adults (Dougherty et al., 1999) suggests that a failure to show DAT decline with age could account for persistence of symptomatology in subjects with ADHD. This could also explain the therapeutic efficacy of MP in adults with ADHD (Solanto, 1998). The age-related blunting in MP-induced DA increases could also reflect a decrease in baseline DA release with aging. It is noteworthy that the age effects were observed in this group of relatively young subjects (24-40 years of age), which indicates that age-related decline in brain DA activity starts to occur before middle age.

\section{Study constraints}

The following constraints need to be considered. (1) This study was done in healthy controls, and although there is no reason to believe that oral MP would not raise extracellular DA in subjects with ADHD, it is possible that the magnitude of this effect will differ from that in controls. It is also possible that chronic treatment with oral MP could affect the magnitude of MP-induced DA changes. (2) This study focused on the effects of MP on DA in striatum, but it is likely that the effects of MP in frontal cortex and its effects on norepinephrine are therapeutically relevant. (3) This study assessed changes in DA induced by MP under resting conditions, whereas the therapeutic effects of MP are made apparent when the subject performs a targeted activity (i.e., classroom work). Thus, similar studies performed when subjects are doing a task are required to better understand the therapeutic effects of MP. This is relevant in that DAergic neurotransmission has both a tonic and a phasic component, and it has been suggested that stimulant drugs differentially affect these two components (Grace, 1995) and that the ability of MP to reduce activity in ADHD subjects is attributable to an attenuation of phasic DA release (Seeman and Madras, 1998). (4) The [ $\left.{ }^{11} \mathrm{C}\right]$ raclopride competition method offers a relative estimate of DA changes, which has been shown to be linearly related to measures of extracellular DA (Breier et al., 1997). However, the precise relationship between extracellular DA and $\left[{ }^{11} \mathrm{C}\right]$ raclopride changes is not known with certainty. (5) Whereas MP-induced changes in extracellular DA as assessed with $\left[{ }^{11} \mathrm{C}\right]$ raclopride have been shown to be reproducible after intravenous administration (Wang et al., 1999), such studies have not been done for oral MP.

This study shows for the first time significant increases in extracellular DA after oral MP in humans. The increase in DA caused by the blockade of the DAT by MP predominantly reflects an amplification of spontaneously released DA. Subjects with ADHD, in whom increased brain levels of DAT are likely to result in rapid removal of DA from the extracellular space, may exhibit deficits of DA that are corrected by treatment with MP.

\section{REFERENCES}

Balster RL, Schuster CR (1973) Fixed-interval schedule of cocaine reinforcement: effects of dose and infusion duration. J Exp Anal Behav 20:119-129.

Biederman J (1998) Attention-deficit/hyperactivity disorder: a life-span perspective. Clin Psychiatry [Suppl 7] 59:4-16.

Booij J, Korn P, Linszen DH, van Royen EA (1997) Assessment of endogenous dopamine release by methylphenidate challenge using iodine-123 iodobenzamide single-photon emission tomography. Eur J Nucl Med 24:674-677.

Breier A, Su TP, Saunders R, Carson RE, Kolachana BS, de Bartolomeis A, Weinberger DR, Weisenfeld N, Malhotra AK, Eckelman WC, Pickar D (1997) Schizophrenia is associated with elevated amphetamineinduced synaptic dopamine concentrations: evidence from a novel positron emission tomography method. Proc Natl Acad Sci USA 94:2569-2574.

Castellanos FX, Elia J, Kruesi MJ, Marsh WL, Gulotta CS, Potter WZ, Ritchie GF, Hamburger SD, Rapoport JL (1996) Cerebrospinal fluid homovanillic acid predicts behavioral response to stimulants in 45 boys with attention deficit/hyperactivity disorder. Neuropsychopharmacology 14:125-137.

Dewey SL, Smith GS, Logan J, Brodie JD, Fowler JS, Wolf AP (1993) Striatal binding of the PET ligand ${ }^{11} \mathrm{C}$-raclopride is altered by drugs that modify synaptic dopamine levels. Synapse 13:350-356.

Dougherty DD, Bonab AA, Spencer TJ, Rauch SL, Madras BK, Fischman AJ (1999) Dopamine transporter density in patients with attention deficit hyperactivity disorder. Lancet 354:2132-2133.

Faraj GA, Israili JM, Perel ML, Jenjins ML, Holtzaman SG, Cucinell SA, Dayton PG (1974) Metabolism and disposition of methylphenidate ${ }^{14} \mathrm{C}$ : studies in man and animals. J Pharmacol Exp Ther 191:535-547.

Gatley JS, Ding Y-S, Volkow ND, Chen R, Sugano Y, Fowler JS (1995) Effects of L-DOPA on striatal uptake of D-threo-[11C]methylphenidate: implications for PET studies. Eur J Pharmacol 281:141-149.

Gerasimov MR, Franceschi M, Volkow ND, Gifford A, Gatley SJ, Marstsellar D, Molina PE, Dewey SL (2000) Neurochemical and locomotor responses to oral and intraperitoneal methylphenidate. J Pharmacol Exp Ther 295:51-57.

Giros B, Jaber M, Jones SR, Wightman RM, Caron MG (1996) Hyperlocomotion and indifference to cocaine and amphetamine in mice lacking the dopamine transporter. Nature 379:606-612. 
Grace AA (1995) The tonic/phasic model of dopamine system regulation: its relevance for understanding how stimulant abuse can alter basal ganglia function. Drug Alcohol Depend 37:111-129.

Greenhill LL Abikoff HB, Arnold E, Cantwell DP, Conners CK, Elliot G, Hechtman L, Hinshaw SP, Hoza B, Jensen PS, March J, Newcorn J, Pelham WF, Severe JB, Swanson JM, Vitiello B, Wells K (1996) Medication treatment strategies in the MTA study: relevance to clinicians and researchers. J Am Acad Child Adolesc Psychiatry 34:1-10.

Kiyatkin EA, Rebec GV (1996) Dopaminergic modulation of glutamateinduced excitations of neurons in the neostriatum and nucleus accumbens of awake, unrestrained rats. J Neurophysiol 75:142-153.

Koob GF (1996) Hedonic valence, dopamine and motivation. Mol Psychiatry 1:186-189.

Krause K, Dresel SH, Krause J, Kung HF, Tatsch K (2000) Increased striatal dopamine transporter in adult patients with attention deficit hyperactivity disorder: effects of methylphenidate as measured by single photon emission computed tomography. Neurosci Lett 285:107-110.

Kuczenski R, Segal DS (1997) Effects of methylphenidate on extracellular dopamine, serotonin, and norepinephrine: comparison with amphetamine. J Neurochem 68:2032-2037.

Laruelle M, Abi-Dargham A, van Dyck CH, Rosenblatt W, Zea-Ponce Y, Zoghbi SS, Baldwin RM, Charney DS, Hoffer PB, Kung HF, Innis RB (1995) SPECT imaging of striatal dopamine release after amphetamine challenge. J Nucl Med 36:1182-1190.

Logan J, Fowler JS, Volkow ND, Wolf AP, Dewey SL, Schlyer D, MacGregor RR, Hitzemann R, Bendriem B, Gatley SJ, Christman DR (1990) Graphical analysis of reversible radioligand binding from timeactivity measurements applied to $\left[\mathrm{N}^{11} \mathrm{C}\right.$-methyl]-cocaine PET studies in human subjects. J Cereb Blood Flow Metab 10:740-747.

Logan J, Volkow ND, Fowler JS, Wang G-J, Dewey SL, MacGregor R, Schlyer D, Gatley SJ, Pappas N, King P, Hitzemann R, Vitkun S (1994) Effects of blood flow on $\left[{ }^{11} \mathrm{C}\right]$ raclopride binding in the brain: model simulations and kinetic analysis of PET data. J Cereb Blood Flow Metab 14:995-1010.

Parran TV, Jasinski DR (1991) Intravenous methylphenidate abuse: prototype for prescription drug abuse. Arch Intern Med 151:781-783.

Oldendorf WH (1992) Some relationships between addiction and drug delivery to the brain. In: Bioavailability of drugs to the brain and the blood brain barrier, NIDA research monograph, Vol 120 (Frankenheim J, Brown RM, eds), pp 13-25. Washington, DC: Government Printing Office.

Overton PG, Clark D (1997) Burst firing in midbrain dopaminergic neurons. Brain Res Brain Res Rev 25:312-334.

Ritz MC, Lamb RJ, Goldberg SR, Kuhar MJ (1987) Cocaine receptors on dopamine transporters are related to self-administration of cocaine. Science 237:1219-1223.

Seeman P, Madras BK (1998) Anti-hyperactivity medication: methylphenidate and amphetamine. Mol Psychiatry 3:386-396.

Shader RI, Harmatz JS, Oesterheld JR, Parmelee DX, Sallee FR, Greenblatt DJ (1999) Population pharmacokinetics of methylphenidate in children with attention-deficit hyperactivity disorder. J Clin Pharmacol 39:775-785.
Solanto MV (1998) Neuropsychopharmacological mechanisms of stimulant drug action in attention-deficit hyperactivity disorder: a review and integration. Behav Brain Res 94:127-152.

Srinivas NR, Hubbard JW, Quinn D, Korchinski ED, Midha K (1991) Extensive and enantioselective presystemic metabolism of dl-threomethylphenidate in humans. Prog Neuropsychopharmacol Biol Psychiatry15:213-220.

Swanson JM, Lerner M, Williams L (1995) More frequent diagnosis of attention deficit-hyperactivity disorder. N Engl J Med 333:944.

Swanson JM, Seargeant JA, Taylor E, Sonuga-Barke EJS, Jensen PS, Cantwell DP (1998) Attention deficit disorder and hyperkinetic disorder. Lancet 351:429-433.

Verebey K, Gold MS (1988) From coca leaves to crack: the effects of dose and routes of administration in abuse liability. Psychiatr Ann 18:513-520.

Volkow ND, Fowler JS, Wang G-J, Dewey SL, Schlyer D, MacGregor R, Logan J, Alexoff D, Shea C, Hitzemann R, Angrist B, Wolf AP (1993) Reproducibility of repeated measures of ${ }^{11} \mathrm{C}$ raclopride binding in the human brain. J Nucl Med 34:609-613.

Volkow ND, Wang G-J, Fowler JS, Logan J, Schlyer D, Hitzemann R, Lieberman J, Angrist B, Pappas N, Mac Gregor R, Burr G, Cooper T, Wolf AP (1994) Imaging endogenous dopamine competition with $\left[{ }^{11} \mathrm{C}\right]$ raclopride in the human brain. Synapse 16:255-262.

Volkow ND, Ding Y-S, Fowler JS, Wang GJ, Logan J, Gatley SJ, Dewey SL, Ashby C, Lieberman J, Hitzemann R, Wolf AP (1995) Is methylphenidate like cocaine? Studies on their pharmacokinetics and distribution in human brain Arch Gen Psychiatry 52:456-463.

Volkow ND, Wang G-J, Fowler JS, Gatley JS, Logan J, Ding Y-S, Hitzemann R, Pappas N (1998) Dopamine transporter occupancies in the human brain induced by therapeutic doses of oral methylphenidate. Am J Psychiatry 155:1325-1331.

Volkow ND, Wang, G-J, Fowler JS, Logan J, Gatley SJ, Wong C, Hitzemann RJ, Pappas N (1999a) Reinforcing effects of psychostimulants in humans are associated with increases in brain dopamine and occupancy of D2 receptors. J Pharmacol Exp Ther 291:409-415.

Volkow ND, Wang GJ, Fowler JS, Gatley SJ, Logan J, Ding Y-S, Dewey SL, Hitzemann R, Gifford A, Pappas N R (1999b) Blockade of striatal dopamine transporters by intravenous methylphenidate is not sufficient to induce self reports of "High." J Pharmacol Exp Ther 288:14-20.

Waldman ID, Rowe DC, Abramowitz A, Kozel ST, Mohr JH, Sherman SL, Cleveland HH, Sanders ML, Gard JM, Stever C (1998) Association and linkage of the dopamine transporter gene and attention-deficit hyperactivity disorder in children: heterogeneity owing to diagnostic subtype and severity. Am J Hum Genet 63:1767-1776.

Wang G-J, Volkow ND, Hitzemann RJ, Wong C, Angrist B, Burr G, Pascani K, Pappas N, Lu A, Cooper T, Lieberman JA (1997) Behavioral and cardiovascular effects of intravenous methylphenidate in normal subjects and cocaine abusers. Eur Addict Res 3:49-54.

Wang G-J, Volkow ND, Fowler JS, Logan J, Pappas NR, Natusil N, Wong CT, Hitzemann RJ (1999) Reproducibility of repeated measures of endogenous dopamine competition with [C-11]raclopride in the human brain. J Nucl Medicine 40:1285-1291. 